\title{
Filosofia no Ensino Médio: um olhar sobre as práticas reformistas na educação brasileira
}

\author{
Philosophy in High School: a look at reformist practices \\ in brasilian education
}

\section{Luana Soares da Silva}

Professora na Escola Municipal Manoel Pereira da Costa, Caracaraí, RR, Brasil. luana_paulinna@outlook.com - https://orcid.org/0000-0001-6220-148X

\section{Nágila dos Santos Situba}

Doutoranda pela Universidade Federal Fluminense, Niterói, RJ, Brasil. nagilasituba@hotmail.com - https://orcid.org/0000-0003-4764-5394

Recebido em 29 de julho de 2019

Aprovado em 24 de maio de 2021

Publicado em 23 de junho de 2021

RESUMO: O presente artigo tem por finalidade discutir o ensino filosófico brasileiro a partir da reforma do ensino médio. Nesse contexto, analisou-se as leis 11.684/2008 e 9.394/96 e as práticas escolares da disciplina de Filosofia, em Caracaraí-RR, assim como suas mudanças no âmbito histórico e educacional. Destacamos ainda partes do processo que a disciplina sofreu ao longo de sua trajetória, sendo esta influenciada pelas ideologias governamentais de cada época, bem como o próprio processo de exclusão e reinserção nas bases curriculares das escolas brasileiras. $O$ método utilizado foi o bibliográfico e os instrumentos de coleta de dados foram as entrevistas. Acredita-se que este trabalho possa fornecer valiosos subsídios para o estudo do ensino de Filosofia no ensino médio, bem como possibilitar a construção de novos pensamentos que permitam ser repensados constantemente durante à construção de um currículo que se aproxime cada vez mais do sentido reflexivo do ato de filosofar.

Palavras-chave: Ensino médio, Reforma educacional, Filosofia.

ABSTRACT: The purpose of this article is to discuss Brazilian philosophical teaching from the reform of high school. In this context, the law 11.684/ 2008 and 9.394/96, the school practices of the discipline of Philosophy, in Caracaraí-RR, were analyzed, as well as its changes in the historical and educational scope. We also highlight parts of the process that the discipline has undergone throughout its trajectory, which is influenced by the governmental ideologies of each era, as well as the process of exclusion and reinsertion in the curricular bases of Brazilian schools. The method used was the 
bibliographic and the data collection instruments were the interviews. It is believed that this work can provide valuable subsidies for the study of Philosophy teaching in high school, as well as enabling the construction of new thoughts that allow it to be constantly rethought during the construction of a curriculum that increasingly approaches the reflexive sense of philosophizing.

Keywords: High school; Educational Reform; Philosophy.

\section{Introdução}

O ensino de filosofia tornou-se objeto de debates, estudos e polêmicas no campo educacional brasileiro, dando mostras de que, efetivamente, temos avançado muito pouco na sua importância para a formação dos estudantes do ensino médio. Partindo da reforma do ensino médio e da lei 11.684/2008, iniciamos a análise de algumas publicações sobre o assunto, fornecidas por alguns sites, incluindo o Ministério da Educação (MEC). Analisamos também documentos entregues ao Conselho Nacional de Educação (CNE) a respeito da $3^{\circ}$ versão da Base Nacional Comum Curricular (BNCC) para o ensino médio, lei sancionada e que tende a promover mudanças estruturais na educação brasileira.

Apesar da Lei de Diretrizes de Bases 9.394/96 apontar para o aperfeiçoamento do educando, a formação ética e o desenvolvimento intelectual crítico, só vigorou com a lei 11.684/2008, quando a disciplina de filosofia se tornou disciplina obrigatória em todo território brasileiro. Esse marco representou um desafio a mais a ser superado não somente pelos teóricos da educação, mas também pela comunidade educacional, a qual precisava demonstrar a necessidade da filosofia e das suas interrelações com as demais áreas do conhecimento, de forma a garantir e fomentar nos educandos competências para que pudessem responder aos desafios impostos pela sociedade contemporânea.

Diante desse cenário, profissionais envolvidos com o ensino, principalmente professores de Filosofia, são convocados a repensar questões fundamentais sobre a disciplina. Esse cenário foi o ponto de partida para buscarmos compreender de que forma é possível introduzir discussões filosóficas, de maneira transdisciplinar, na educação brasileira; e por que se deve ensinar filosofia para os jovens do ensino médio, 
e quais conteúdos e metodologias devem ser ministradas para atingir tais objetivos. Sobre tais questões, Kohan (2002, p.22) afirma,

\begin{abstract}
Não considero interessante apenas que a filosofia ocupe espaços. Dentro e fora das escolas, importa, fundamentalmente, compreender o que ela faz nesses espaços, o tipo de filosofia que se pratica (e ensina), sua relação com outras áreas do saber, com a instituição escolar e as outras instituições da vida econômica, social e política do país. Convém, especificamente, considerar a relação que professores e alunos envolvidos com a filosofia estabelecem entre si e com ela. Importa, antes de mais nada, o tipo de pensamento que se afirma e se promove sob o nome de filosofia.
\end{abstract}

Nesse seguimento, pensar filosoficamente tem sido um dos desafios, principalmente no âmbito escolar. Pretendemos discutir o ensino filosófico brasileiro, a partir da reforma do ensino médio, verificando de que forma as escolas podem aproveitar e introduzir discussões filosóficas de maneira transdisciplinar, de modo que esta não seja apenas mais uma disciplina singular, mas que proporcione aos envolvidos a capacidade de reflexão e uma visão diferenciada de mundo, criando ideias e atitudes que consigam ir além do senso comum.

Os objetivos específicos consistiram em verificar a efetivação das mudanças no ensino de filosofia com a reforma do ensino médio; analisar quais os aspectos positivos e negativos da reforma do ensino médio; e investigar como estão sendo aplicados os conteúdos e se os mesmos estão contribuindo para uma aprendizagem significativa.

O interesse por esse tema surgiu da necessidade de discutir as leis e a importância da Filosofia para a realização e o desenvolvimento de habilidades. A Filosofia deve ter espaço no ensino médio, pois sua presença nas escolas, sem dúvida, é de suma importância na construção do pensamento crítico do aluno, seja por utilidade ou por um agrado imediato, que qualidades como o pensamento crítico e a autonomia intelectual devem ser visadas pela educação. Dessa forma, a disciplina de filosofia no ensino médio mostra-se como um saber capaz de provocar inter-relações entre as áreas do conhecimento, reflexões e mudanças necessárias para a construção da autonomia do educando (BRASIL, 2000; 2006). 
Em 2018, foi anunciada ao Conselho Nacional de Educação (CNE) a Base Nacional Curricular Comum do Ensino Médio (BNCC/EM), que apresenta as novas propostas do Ministério da Educação (MEC), as quais além de despertarem a criticidade, também contribuem na construção de um ser humano com princípios éticos e democráticos. No entanto, devido às mudanças ocasionadas pela reforma, surgiu a necessidade de investigarmos até que ponto essas mudanças podem ser benéficas ou maléficas aos alunos.

\section{Metodologia}

O desenvolvimento deste trabalho deu-se através de uma investigação, possui cunho bibliográfico e de pesquisa de campo e essencialmente qualitativo. Averiguamos, através de dados obtidos em sites oficiais do MEC, as recentes mudanças relacionadas à disciplina de filosofia a partir da medida provisória do Governo Temer, bem como da emenda da câmara dos deputados, no sentido de descobrir se tais mudanças já estão em funcionamento no sistema educacional brasileiro. As escolhas teóricas tiveram como ponto de partida autores que discutem a temática e todas as leis abordadas serviram de base para a compreensão dessas mudanças no cenário educacional. Com o intuito de analisar essas mudanças no ensino médio, analisamos duas escolas estaduais de ensino médio, de modo a obter informações a respeito dessas transformações no âmbito da disciplina de filosofia.

\section{Resultados e discussões}

Quando nos referimos à história do Brasil, observamos que a Filosofia é basicamente aquilo que acontece desde a chegada dos jesuítas. Os jesuítas ${ }^{1}$ foram os responsáveis junto à igreja pela fundação das primeiras instituições de ensino e, especificamente, dos primeiros colégios que ensinavam filosofia.

Historicamente, ao longo do processo de transição dos Jesuítas, aqui no Brasil, a filosofia foi tratada pelo modo concebido no estilo de reflexão de matriz grega e apenas de modo acadêmico. Dessa maneira, a filosofia brasileira, seguindo o movimento 
histórico, divide-se em longos momentos: período colonial, período imperial e o período republicano. Cada período contribuiu de forma significativa para a evolução do pensamento filosófico.

No período dos jesuítas, a filosofia era basicamente baseada no ensino de teologia, desvinculado da realidade, era somente o simples estudo das obras e não havia abertura para um estudo e interpretação do pensamento, configurando-se como um estudo rígido e formalístico.

Ao longo da pesquisa, observamos que a Filosofia, no Brasil, é, por sua vez, uma filosofia propriamente brasileira, como pode ser observado, por exemplo, na relação entre o jovem da periferia que se torna jogador de futebol e sendo esse mesmo um formador de opinião para jovens mais novos, ou ainda, brasileiros que filosofam sobre questões, sejam particulares do Brasil, mas que tendo em si, uma característica original e própria de algum filósofo, em seu tempo esse jovem se idealiza, que pode mudar sua realidade por meio dessa conquista, sendo que os de classe média já se dão conta que só se pode mudar através da educação, de sua formação. Vale salientarmos que é muito importante considerarmos que toda filosofia traz em si a marca de um tempo e de um lugar, vejamos o que afirma GOMES, 1994 apud OLIVEIRA, 2015, p. 93.

Fora, portanto, das urgências de seu tempo, os pensadores não chegam a fazer pleno sentido. Mas não basta ressaltar que todo pensamento traz a marca de seu lugar e tempo - isto, de um modo ou de outro, muitos aceita. O vital é reconhecermos que um pensamento é original não por superar sua posição - o que é impossível -, mas precisamente por dar forma e consistência a este tempo e apresentar uma revisão crítica das questões de sua época, aí tendo origem. O pensamento é superior não a despeito de ser situado, mas justamente por situar-se.

Ao lermos sobre a história da filosofia no Brasil, percebemos a relevância e pertinência da afirmação de Gomes (1994) no excerto supracitado, pois entendemos que há uma necessidade na filosofia brasileira (OLIVEIRA, 2015).

Neste contexto, "a contemporaneidade é esse labirinto [...] Afinal de contas, ser contemporâneo, nas condições descritas pelo filósofo, é ter a condição de enxergar, no presente, as luzes das sobras e as sobras das luzes" (SANTOS; NEITZEL, 2015, p. 74). Complementando, 
A contemporaneidade é uma singular relação com o próprio tempo, que adere a este e, ao mesmo tempo, dele toma distâncias; mais precisamente, essa é a relação com o tempo que a este adere através de uma dissociação e um anacronismo. Aqueles que coincidem muito plenamente com a época, que em todos os aspectos a esta aderem perfeitamente, não são contemporâneos porque, exatamente por isso, não conseguem vê-la, não podem manter fixo o olhar sobre ela. (AGAMBEN, 2009 apud SANTOS; NEILTZEL, 2015, p.74).

A contemporaneidade, por meio do tempo, cristaliza-se no cotidiano, induzindo mudanças e possibilidades entre o sujeito e o objeto. "Entretanto, os sujeitos continuam sendo raros. Uma das razões para isso talvez esteja no fato da contemporaneidade criar "tipos", "caricaturas" de pessoas que recebem o título de sujeitos (SANTOS; NEILTZEL, 2015, p.74). Essas raridades dos sujeitos recaem sobre todos nós que buscamos entender a complexidade da contemporaneidade. Para os autores,

\begin{abstract}
Acreditamos na vivência dessas experiências e na fundamentação desse querer, por isso nos incluímos aos contemporâneos e não contemporâneos da contemporaneidade e propomos uma formação filosófica que nos permita fazer um recuo do presente para não seguirmos alheios ao nosso tempo. Sim, sabemos das exigências dessa postura, mas, por mais paradoxal que isso possa parecer, não nos parece que fugir dessa realidade seja a solução mais adequada. A filosofia como uma forma de vida poderá não ser a realidade de uma geração, mas se ela tiver esse desejo, mais do que abrir e alargar caminhos para quem está caminhando, deixará um caminho aberto para quem virá depois. (SANTOS; NEILTZEL, 2015, p. 7677).
\end{abstract}

Esse olhar que devemos ter da filosofia nos dias atuais são motivados por experiências individuais e coletivas, partindo de uma construção social, que leva em consideração o lugar, o vivido e o percebido. Para Gramsci (1978, p.12), no livro "Concepção Dialética da História”, 
É preferível pensar sem disto ter uma consciência crítica, de uma maneira desagregada e ocasional, isto é, participar de uma concepção de mundo "imposta" mecanicamente pelo ambiente exterior, ou seja, por um dos vários grupos sociais nos quais todos estão automaticamente envolvidos desde sua entrada no mundo consciente. Ou é preferível elaborar a própria concepção do mundo de uma maneira critica e consciente e, portanto, em ligação com este trabalho próprio do cérebro, escolher a própria esfera de atividade, participar ativamente na produção da história do mundo, ser o guia de si mesmo e não aceitar do exterior, passiva e servilmente, a marca da própria personalidade.

A disciplina de filosofia consegue estimular essa consciência crítica nos indivíduos, de maneira que eles criem a sua própria ideia de mundo e a sua compreensão da realidade. Em virtude do que objetivamos neste trabalho, entendemos que a filosofia ao longo do tempo vem se reestruturando de acordo com a demanda, evitando que a reformulação impeça uma imposição. A filosofia vem fazendo com que o ser humano busque seu sentido na vida, movido pela busca de uma explicação de mundo ou de si próprio, essa intermitência que a filosofia vem sofrendo causa grandes implicações, em decorrência de sua busca pelo foco da problemática relacionada à existência do ser humano. O profissional que trabalha com ensino de filosofia tem desafios, pois o seu papel é auxiliar o educando na construção do conhecimento em seu processo de amadurecimento de suas decisões e em meio ao exercício de cidadania.

É possível verificar, na resposta dos coordenadores à questão 1 - Como era visto o ensino de filosofia no ensino médio antes da retirada da obrigatoriedade? - Um conceito um tanto aparente por parte dos mesmos, como podemos observar nas respostas a seguir:

\footnotetext{
Antes a filosofia tinha a missão na escola de apresentar aos alunos "abertura de espírito para entender que a verdade nunca está de um lado só". (Coordenador 1)

A história de intermitência da filosofia no ensino médio, contribuiu de forma significativa para que a mesma não tivesse importância no cenário educacional, tanto por parte do corpo discente, como também para professores de outras disciplinas. (Coordenador 2)
}

Ao analisar as respostas obtidas nesta questão, fica claro que os coordenadores têm ciência do real papel da filosofia enquanto disciplina, porém, observa-se que a disciplina é trabalhada, em sala, de acordo com cada proposta e não se nota que a 
mesma seja vista de forma a transformar o aluno em um ser crítico. Esta análise vai ao encontro da citação do autor:

\begin{abstract}
É assim que vemos a Filosofia reduzir-se a um dos seus conteúdos e o papel do professor de Filosofia diluir-se entre todos os demais - a natureza interdisciplinar da Filosofia parece mesmo ter sido um bom argumento para um discurso que justifica sua presença em todo e em nenhum lugar, reservando a ela um estilo onipresente. Como um Deus, ela está no meio de nós - mas não podemos vê-la em lado nenhum. (OLIVEIRA, 2004 apud SANTOS, 2015, p.65).
\end{abstract}

Com a aprovação da Lei de Diretrizes e Bases da Educação, no ano de 1996, a disciplina de filosofia passa a ganhar novos olhares não apenas dentro da escola, mas também for a dela. Ao sair do Ensino Médio, o aluno deve entender os conteúdos de Filosofia e de Sociologia para o exercício da cidadania

Na resposta dos coordenadores à questão 2 - Como o ensino de filosofia passou a ser visto a partir das práticas reformistas na educação brasileira? É possível evidenciar o quanto a reforma deu abertura para novas reflexões.

Após a reforma a filosofia deu abertura para reflexões de temas da atualidade que leva o aluno a refletir sobre a vivência atual, porém se essas aulas de filosofia não forem bem mediadas, corre o risco de termos os debates livres sem nenhuma reflexão. (Coordenador 1 )

Acredito que as práticas reformistas evidenciaram o ensino da filosofia como indispensável, devido as suas contribuições para a formação cidadã, como bem cita a LDB. (Coordenador 2)

Nessa perspectiva, os conhecimentos de Filosofia e Sociologia são justificados, de acordo com a LDB, como necessários ao exercício da cidadania. Isso se modificará com a implantação dos PCNS e OCNS, bem como de documentos diversos do MEC. "Os PCN vigentes para a disciplina, assim como os anteriores, sofrem da ambiguidade que pretenderam curar e muitas vezes oscilam entre enunciar pouco e enunciar excessivamente". (BRASIL, 2006, p. 18).

Em junho de 2008, mais precisamente no dia 2, foi aprovada a lei 9394/96 que alterou o artigo 36 da LDB: "IV - serão incluídas a filosofia e a sociologia como disciplinas obrigatórias em todas as séries do ensino médio" (BRASIL, 2008). 
$\mathrm{Na}$ resposta dos gestores à questão 3 - Como vem se dando na sala de aula, a efetivação das mudanças no ensino de filosofia com a reforma do ensino médio? -, Notase que todos estão comprometidos nessa busca pelo cumprimento da melhoria do ensino de filosofia, esperando que o cidadão seja capaz de compreender as questões objetivas e práticas do seu cotidiano.

A efetivação do ensino de filosofia se dar ao levar a escola a necessidade de ensinar a pensar e fazer análises embasadas em temáticas atuais. (Coordenador 1 )

Com a reforma, a filosofia ganha espaço no estudo de quem realmente não só se preocupa com a formação cidadã e o papel crítico do indivíduo, com também para aqueles que desejam ingressar no ensino superior por meio do ENEM. (Coordenador 2)

A filosofia, no ensino médio, contribui para "aprimoramento como pessoa humana, incluindo a formação ética e o desenvolvimento da autonomia intelectual e do pensamento crítico" (BRASIL, 1996).

A base nacional comum curricular veio com a inquietação de formar cidadãos críticos e autônomos para que tomem decisões conscientes e responsáveis, porém, essa retirada da obrigatoriedade do ensino causa-nos grandes preocupações na questão da diluição dos conteúdos nas demais disciplinas.

$\mathrm{Na}$ questão 4 - Quando questionado sobre quais os aspectos positivos e negativos dessa reforma no ensino médio? -, os coordenadores falaram dos pontos positivos e negativos da reforma.

Ponto negativo: o ministério da educação não define exatamente o que deve ser ensinado. Ponto positivo: os professores podem recorrer a temas que envolvem vidas, cidadania e arte. (Coordenador 1)

Positivos: o interesse do aluno pelo aprendizado da respectiva disciplina e a importância que ganhou o profissional de filosofia. Negativos: a filosofia é mãe de todas as ciências, portanto, todos deveriam estudar e compreender a contribuição da mesma para a vida, e não somente uma parte do público discente. (Coordenador 2)

Os aspectos positivos e negativos colocam em evidências o quanto é preciso haver mudanças no planejamento dos conteúdos. O ensino de filosofia recorre a temas transversais, como: cidadania, ética e cotidiano. 
Na questão 5 - Quando foi indagado ao coordenador de que forma estão sendo aplicados os conteúdos e de que forma os mesmos estão contribuindo para uma aprendizagem significativa dos alunos? Os docentes responderam da seguinte maneira:

\begin{abstract}
Estão sendo aplicados de forma reflexivos. Se a aula foi bem mediada, sim, terá um grande significado na aprendizagem do aluno, pois, a reflexão gera transformação de hábitos e atitudes. (Coordenador 1)

Nas escolas a filosofia era aplicada de forma a tornar o indivíduo crítico, autor de sua história no cenário social. No ensino médio, especialmente, os conteúdos são trabalhados de maneira crítica, porém compreendo as correntes filosóficas estudadas e que são cobradas. Coordenador 2
\end{abstract}

Nota-se que, nas escolas estaduais do município de Caracaraí, a disciplina de filosofia é trabalhada aquém do seu real papel filosófico, o de buscar a transformação do educando, para que o mesmo venha a transformar seu meio social.

Com a reforma do ensino médio, foi debatida a obrigatoriedade do ensino de filosofia. Esse processo de intermitência causa grandes prejuízos para a educação, pois, na medida que a disciplina propõe uma reflexão embasada sobre a participação política, sobre a atualidade e a relação de poder, aluno tem que esta munido de todo um aparato, no que concerne ao conteúdo, tornando o indivíduo apto a uma participação ativa, cumprindo o seu papel civil em a sociedade.

\title{
Considerações finais
}

A volta da filosofia aos currículos das escolas brasileiras é de grande relevância, pois a sua contribuição no processo de formação dos sujeitos é significativa, no sentido de auxiliá-los no exercício da cidadania. Parece evidente que a estratégia de explicitar a história da filosofia é muito acertada. Espera-se que os jovens sejam capazes de perceber sua posição no mundo e na sociedade, e ainda sejam capazes de colocar-se criticamente frente aos problemas do mundo atual e do seu país.

Dessa forma, podemos auxiliar os jovens a posicionarem-se filosoficamente diante sua vida e do mundo moderno, mostrando os exemplos vivenciados em sua trajetória. A nossa esperança é que, apoiando-se nos relatos e nas experiências vividas por esses homens representantes das gerações anteriores, nossos educandos consigam ver além dos horizontes. Observa-se que a prática do ensino da filosofia tem 
ocupado novos espaços nos meios educacionais nos últimos anos e, por isso mesmo, demanda constantemente uma avaliação sistematizada.

Assim, observa-se que a filosofia é de grande importância no ambiente escolar, tornando o aluno um ser crítico, o que pode trazer grandes contribuições para as novas gerações, tornando-as consciente de seu papel em meio à sociedade atual, pois a filosofia tem por objetivo promover um agir e um conhecer além da reprodução. Entretanto, seu futuro parece incerto, pois a BNCC, ao retirar a sua obrigatoriedade, deixa a decisão nas mãos das instituições de ensino.

\section{Referências}

BRASIL. Lei de Diretrizes e Bases da Educação Nacional/ n 9.394, de 20 de dezembro de 1996. Disponível em: http://www.planalto.gov.br/ccivil_03/leis//9394.htm. Acesso em: mar. 2019.

BRASIL. Lei 11.684/2008. Disponível em: <http://www.planalto.gov.br/ccivil_03/_ato2007-2010/2008/lei/l11684.htm>. Acesso em: dez. 2019.

BRASIL. Ministério da Educação e do Desporto. Secretaria de Educação Média e Tecnológica. Parâmetros Curriculares Nacionais para o Ensino Médio. Brasília: MEC/SEMTEC, 2000. Disponível em:

<http://portal.mec.gov.br/seb/arquivos/pdf/14_24.pdf>. Acesso em: set. 2020.

BRASIL. Ministério da Educação e do Desporto. Secretaria de Educação Básica.

Ciências humanas e suas tecnologias. Brasília: MEC, volume 3, 2006. 133p.

(Orientações curriculares para o ensino médio). Disponível em:

$<$ http://portal.mec.gov.br/seb/arquivos/pdf/book_volume_03_internet.pdf>. Acesso em dez.2019.

BACCON, Ana Lúcia Pereira; GABRIEL, Fábio Antônio. O retorno da Filosofia ao Ensino Médio no Brasil. In: X FERREIRA, A.L.S. Ensino de filosofia: a história da filosofia e a prática no mundo. In: GOMES, Roberto. A crítica da razão tupiniquim. 11. Ed. São Paulo: FTD, 1994, p. 21.

OLIVEIRA, Pedro Hermes de. Filosofia no ou do Brasil. Pensar: Revista Eletrônica da FAJE, v. 6, p. 91-102, 2015.

GRAMSCI, Antonio. Concepção dialética da história. 3. ed. Rio de Janeiro: Civilização Brasileira, 1978. 
KOHAN, Walter. O Ensino de Filosofia. Perspectivas. 1. ed. Belo Horizonte: Autêntica, 2002. v. 1. 298p.

RODRIGUES, Zita Ana Lago. O Ensino de Filosofia no Brasil no Contexto das políticas educacionais contemporâneas em suas determinações legais e paradigmáticas. Educar em Revista (Impresso), v. 1, p. 69-82, 2012.

SANTOS, Claudecir; NEITZEL, Odair. O lugar da filosofia na contemporaneidade.

GRIOT, v. 12, p. 66-78, 2015.

SANTOS, Yvisson Gomes dos. Os documentos oficiais sobre a disciplina de filosofia no ensino médio: uma análise teórica. Saberes (Natal), v. 01, p. 64-77, 2015.

OLIVEIRA, Renato José. O livro didático de filosofia em foco. In: FRIGOTTO,

Gaudêncio; CIAVATTA, Maria (Org.). Ensino Médio: ciência, cultura e trabalho. Brasília: MED, SEMTEC, 2004, p. 253 -275.

\section{Notas}

1 Um dos mais famosos o Pe. José de Anchieta.

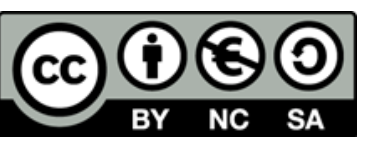

This work is licensed under a Creative Commons Attribution-NonCommercial 4.0 International (CC BYNC 4.0) 